\title{
The effect of early antenatal booking on adherence to Iron/folic acid supplementation among antenatal care attendees in Libo kemkem district, Ethiopia
}

Tewachew Muche liyeh ( $\square$ tewye2006@gmail.com )

Debre Tabor University

Yitayal Ayalew Goshu

Debre Tabor University

Amare Simegn Ayele

Debre Tabor University

Yibeltal Abebe

Bahir Dar University

Research article

Keywords: Iron-folic acid, adherence and pregnant women

Posted Date: August 19th, 2019

DOI: https://doi.org/10.21203/rs.2.13116/v1

License: (c) (i) This work is licensed under a Creative Commons Attribution 4.0 International License.

Read Full License 


\section{Abstract}

Background Iron and folic acid supplementation is the feasible and cost effective strategy to control and prevent anemia in pregnancy. Pregnant women are vulnerable for iron deficiency anemia due to increased nutrient requirement during pregnancy. In Ethiopia, the national data suggests that from all pregnant women supplemented with these tablets, only $5.1 \%$ consumed more than 90 tablets during their pregnancy time. The factors for this low adherence are not clearly known. Objective: To assess factors associated with adherence to iron-folic acid supplementation among pregnant women attending antenatal care service in Libo Kemkem district, Ethiopia 2017. Method: Hospital based cross sectional study was conducted using quantitative methods on 406 pregnant women attending antenatal care at Libo Kemkem district public health institutions. Systematic random sampling method was used. An interview with pre tested semi structured questionnaire was carried out. The collected data was entered in Epi data 4.1 and analyzed with SPSS version 20. Bivariate and multivariable logistic regression model were used. Odds ratio with $95 \%$ interval was computed and P-value $<0.05 \%$ considered as level of significance. Result: About 406 respondents were included in the study. The adherence rate of iron-folic acid supplementation was $49.3 \%(95 \% \mathrm{Cl}=44.3 \%-54.2 \%)$. Factors significantly associated with adherence to iron-folic acid utilization were urban residence ( $A O R=4.8,95 \% \mathrm{Cl}=1.82-12.79$ ), women aged 21-30 $(\mathrm{AOR}=4.3,95 \% \mathrm{Cl}=1.60-11.42)$, women aged 31-40 (AOR =4.2, 95\% $\mathrm{Cl}=1.33-13.41)$,early ANC booking ( $A O R=4.1,95 \% \mathrm{Cl}=1.80-9.30)$ and getting medical advice $(\mathrm{AOR}=2.5,95 \% \mathrm{Cl}=1.04-6.16)$. Fear of side effects, forgetfulness and too many pills were the major reasons for missing the doses of tablets. Conclusion: adherence rate of iron and folic acid supplementation was low. Residence, maternal age, early ANC booking and getting medical advice were significantly associated with adherence to iron and folic acid. Key Words: Iron-folic acid, pregnant women and adherence

\section{Background}

Iron-deficiency anemia is an important public health problem affecting all population segments especially pregnant women $(1,2)$. During pregnancy there is an increase of iron and folate demands, therefore probability of presenting iron deficiency and folate deficiency is high if there is not supplementation during the pregnancy (3).

Evidences showed that globally around $41.8 \%$ of pregnant women are anemic $(4,5)$. According to the 2016 report of Ethiopian Demographic and Health Survey (EDHS), anemia is plentiful among the pregnant and non-pregnant mothers in the country, where, $24 \%$ of women are anemic (6).

Iron deficiency anemia contributes to unfavorable effects on maternal and child health, including risk of hemorrhage, infection, miscarriages, low birth weight, fetal distress and neural tube defect. It also impairs children's physical and cognitive development, further impacting economic productivity and development of the country $(7,8)$. 
According to World Health Organization (WHO) recommendation all pregnant women should take a standard dose of $60 \mathrm{mg}$ Iron and $400 \mu \mathrm{g}$ Folic acid during gestation as part of their ANC follow up (9). The Ethiopian Ministry of health also recommends daily IFA supplementation for at least 6 months during pregnancy and 3 months postpartum (10). The adherence of IFA tablets plays a major role in limiting maternal and newborn mortality and morbidity related to iron deficiency anemia.

In Ethiopia, studies on the level of adherence and factors associated were limited in number and showed discrepancy within the area and among different populations (11-13) and also the factors contributing for this low level of adherence have not been well studied in the country. Therefore, we conducted this study to find out the level of adherence to iron and folic acid supplementation during pregnancy and associated factors in Libo Kemkem district, Ethiopia.

\section{Methods}

Study design and setting

Hospital based cross sectional study was conducted in Libo kemkem district from November to December 2017. Libo Kemkem district is found in Amhara Region, Ethiopia. The district has a total of 33 kebeles and the estimated total population is 227,069 of whom 115, 830 male and 111, 239 female. Regarding to health services, the district has one district hospital, nine health centers and 33 health posts. There were around 8948 pregnant women were present in the district.

\section{Participants}

The source population was all pregnant women attending ANC clinic in all health institution in Libo kemkem district and the study population was all pregnant women attending ANC clinic in selected health facilities during the study period. Women attending ANC for the first time was excluded from the study.

\section{Sample Size Determination and Sampling Procedure}

The sample size was calculated using single population proportion formula by assuming $59.8 \%$ of women adhered for iron and folic acid from previous similar study with 95\% confidence interval, $5 \%$ marginal error and $10 \%$ non response rate. The sampled 406 pregnant women were selected by systematic sampling technique. According to the health institutions report, the average cases flow for ANC clinic is 820 per month in four health facilities. The value was $701 / 406$ which is equal to 1.73 , so every 2 nd woman was asked. The first candidate was select by lottery method from each health facility.

\section{Data Collection Tools and Techniques}

Data for this study were collected by using face to face interview. The questionnaire was adapted after reviewing pertinent previous literatures. The questionnaire was first developed in English and transferred to local language (Amharic) then back to English by language experts to keep its consistency. The data 
was collected by 4 diploma midwives after one day training about informed consent, techniques of interviewing, data collection procedures, and different sections of the questionnaire. Two BSc Midwives were assigned as supervisors for the data collectors. Overall supervision also made by the principal investigators. Before starting the actual survey, the questionnaire was pre-tested on $5 \%(20)$ individuals outside the study area and the necessary modification on the questionnaire and data collection procedures made. The collected data was reviewed and checked for completeness before data entry and the incomplete data was discarded.

\section{Operational Definition}

A woman who had taken iron/folic acid tablet at least four days in the previous one week prior to data collection time considered as adherence on IFA otherwise non-Adherence. Those pregnant women who visited the ANC clinic before 16 weeks of gestation is said to be early registration (early booking) to ANC but a woman who visited ANC clinic after 16 weeks of gestation considered as late registration(late booking) to ANC (1).

\section{Data analysis}

The data were entered into Epi data statistical software version 3.1 and then analyzed by using SPSS version 20 statistical package. Descriptive statistics was done to describe the study population in relation to relevant variables by using tables and graphs. Bivariate analysis was done for all explanatory variables in relation to adherence of iron and folic acid utilization, and those variables with $P<0.2$ were entered in to multivariable logistic regression for analysis adjustment of confounding effect between explanatory variables. Adjusted odds ratio with $95 \%$ confidence interval was computed and P-value less than 0.05 considered as level of significance.

\section{Ethical clearance}

Ethical clearance was obtained from ethical review board of Debre Tabor University and permission was obtained from Libo kemkem district health office. Then the Participants of the study were informed about the purpose of the study, the importance of their participation, and their right to withdraw at any time. Written informed consent was obtained for age group > 18 year old and parental consent was obtained for age less than 18 year old prior to data collection. Confidentiality of the information was maintained throughout by using anonymity identifiers, keeping their privacy by interviewing them individually

\section{Results}

Socio-demographic Characteristics of pregnant women

A total of 406 pregnant women were participated and the response rate was $100 \%$. The mean (+SD) age of the respondents was found to be $28.3+9.04$ years and half of the study participants $216(53.2 \%)$ were 20-29 years. Majority 314 (77.3\%) of the study population were from urban area. More than half, 228 
(56.2\%) were orthodox Christian in religion and all of the participants were married. About $168(41.4 \%)$ had education level of secondary and above. Nearly half (47\%) of the study participants were house wife.

Table 1: Socio-demographic characteristics of respondents about iron with folic acid adherence in Libo Kemkem district, 2017.

\begin{tabular}{|c|c|c|c|}
\hline Variable & Category & Frequency & Percent \\
\hline \multirow[t]{3}{*}{ Age } & $\begin{array}{l}15-19 \\
20-29\end{array}$ & 40 & $\begin{array}{l}9.9 \\
532\end{array}$ \\
\hline & $30-39$ & 134 & 33.0 \\
\hline & $40-49$ & 16 & 3.9 \\
\hline \multirow[t]{3}{*}{ Religion } & Orthodox & 228 & 56.2 \\
\hline & Muslim & 138 & 34.0 \\
\hline & Protestant & 40 & 9.9 \\
\hline \multirow[t]{2}{*}{ Residence } & Rural & 92 & 22.7 \\
\hline & Urban & 314 & 77.3 \\
\hline \multirow[t]{4}{*}{ Educational status } & Cannot read and write & 116 & 28.6 \\
\hline & Can read and write & 74 & 18.2 \\
\hline & Primary education & 48 & 11.8 \\
\hline & Secondary and above & 168 & 41.4 \\
\hline \multirow[t]{4}{*}{ Occupational status } & House wife & 191 & 47.0 \\
\hline & Daily laborer & 8 & 2.0 \\
\hline & Government employee & 88 & 21.7 \\
\hline & Merchant & 119 & 29.3 \\
\hline Marital Status & Married & 406 & 100 \\
\hline Partner & Cannot read and write & 38 & 9.4 \\
\hline \multirow{3}{*}{ Educational status } & Can read and write & 103 & 25.4 \\
\hline & Primary education & 42 & 10.3 \\
\hline & Secondary and above & 223 & 54.9 \\
\hline \multirow[t]{3}{*}{ Family size } & $1-3$ & 230 & 56.7 \\
\hline & $4-6$ & 105 & 25.9 \\
\hline & $>6$ & 63 & 15.5 \\
\hline \multirow[t]{5}{*}{ Family income } & 750-1400 birr & 179 & 44.1 \\
\hline & 1401-2350 birr & 129 & 31.8 \\
\hline & 2351-3550birr & 50 & 12.3 \\
\hline & $3551-5000$ birr & 42 & 10.3 \\
\hline & $>5000$ birr & 6 & 1.5 \\
\hline
\end{tabular}

Obstetric and Health Facility related characteristics of pregnant women

The mean + SD gestational age of the study subjects was $7.27+1.43$ months. Two thirds $271(66.8 \%)$ of the respondents were in their third trimester. About $143(35.2 \%)$ of the participants were prim gravidas and $263(64.8 \%)$ were multiparous. More than two third 295(72.7\%) of the respondents visited the ANC clinic within their 16 weeks of gestation. About 190(46.8) of the respondents had two ANC visits. About $195(49 \%)$ of the respondents spent more than 30 minutes (by foot) to reach the health facility and $347(85.5 \%)$ of the respondents got medical advice about IFAS. 
Table 2: Obstetric and health facility related characteristics of Pregnant women attending ANC clinics in, Libo Kemkem District, 2017.

\begin{tabular}{llll}
\hline Variable & Category & Frequency & Percent(\%) \\
\hline Gravidity & Primi gravid & 143 & 35.2 \\
& Multigravida & 263 & 64.8 \\
\cline { 2 - 4 } Trimester & First & 24 & 5.9 \\
\cline { 2 - 4 } & Second & 111 & 27.3 \\
\cline { 2 - 4 } & Third & 271 & 66.8 \\
\hline Time of registration & $<16$ weeks (Early) & 295 & 72.7 \\
\cline { 2 - 4 } & $\geq 16$ weeks (Late) & 111 & 27.3 \\
Number of Visits & $<4$ & 350 & 86.2 \\
\cline { 2 - 4 } Distance from health facility & 4 & 56 & 13.8 \\
\cline { 2 - 4 } & $>30$ minutes & 211 & 51 \\
Get Medical advice about IFAS & 195 & 49 \\
\cline { 2 - 4 } & Yes & 347 & 85.5 \\
\cline { 2 - 4 } & No & 59 & 14.5 \\
\hline
\end{tabular}

Adherence to IFA supplementation of the respondents

Adherence level was determined by self-report questions among 406 pregnant women. Two hundred six $((49.3 \%(95 \% \mathrm{Cl}=44.3 \%-54.2 \%))$ women were adhered (took IFA greater than or equal to four days in the previous one week prior to data collection). The primary underlying reasons for the non-adherence of IFA among the pregnant women were fear of side effects 99 (49.5\%), forgetfulness $66(33 \%)$ and unaware of the importance of IFA 35 (17.5-\%).

\section{Factors associated with adherence of IFA utilization}

Twenty variables were tested in bivariate logistic regression to see the association between dependent and dependent variables. Only ten variables were found to be significantly associated $(p=<0$. 2$)$ with adherence of IFA utilization. In multivariable logistic regression only women's age, residence, time of ANC booking and getting medical advice were significantly associated with adherence of IFA utilization

Compared to women who live in the rural areas, those women living in the urban areas were about 4.8 times $(\mathrm{AOR}=4.8,95 \% \mathrm{Cl}=1.82-12.79)$ more likely to be adhered with IFA utilization.

Compared to women aged 15-19, those women women aged 21-30 and women aged 31-40 were about 4.3 times $(A O R=4.3,95 \% \mathrm{Cl}=1.60-11.42)$ and 4.2 times $(A O R=4.2,95 \% \mathrm{Cl}=1.33-13.41)$ more likely to be adhered with IFA utilization respectively.

Women having early ANC booking were about 4.1 times $(A O R=4.1,95 \% \mathrm{Cl}=1.80-9.30)$ more adhered for IFA utilization than women having late ANC booking. 
Women who had got medical advice about IFA utilization were 2.5 times $(A O R=2.5,95 \% \mathrm{Cl}=1.04-6.16)$ more likely to be adhered than who didn't get medical advice.

Table 3: factors associated with adherence to IFAS among Pregnant women attending ANC clinics in Libo kemkem district, 2017.

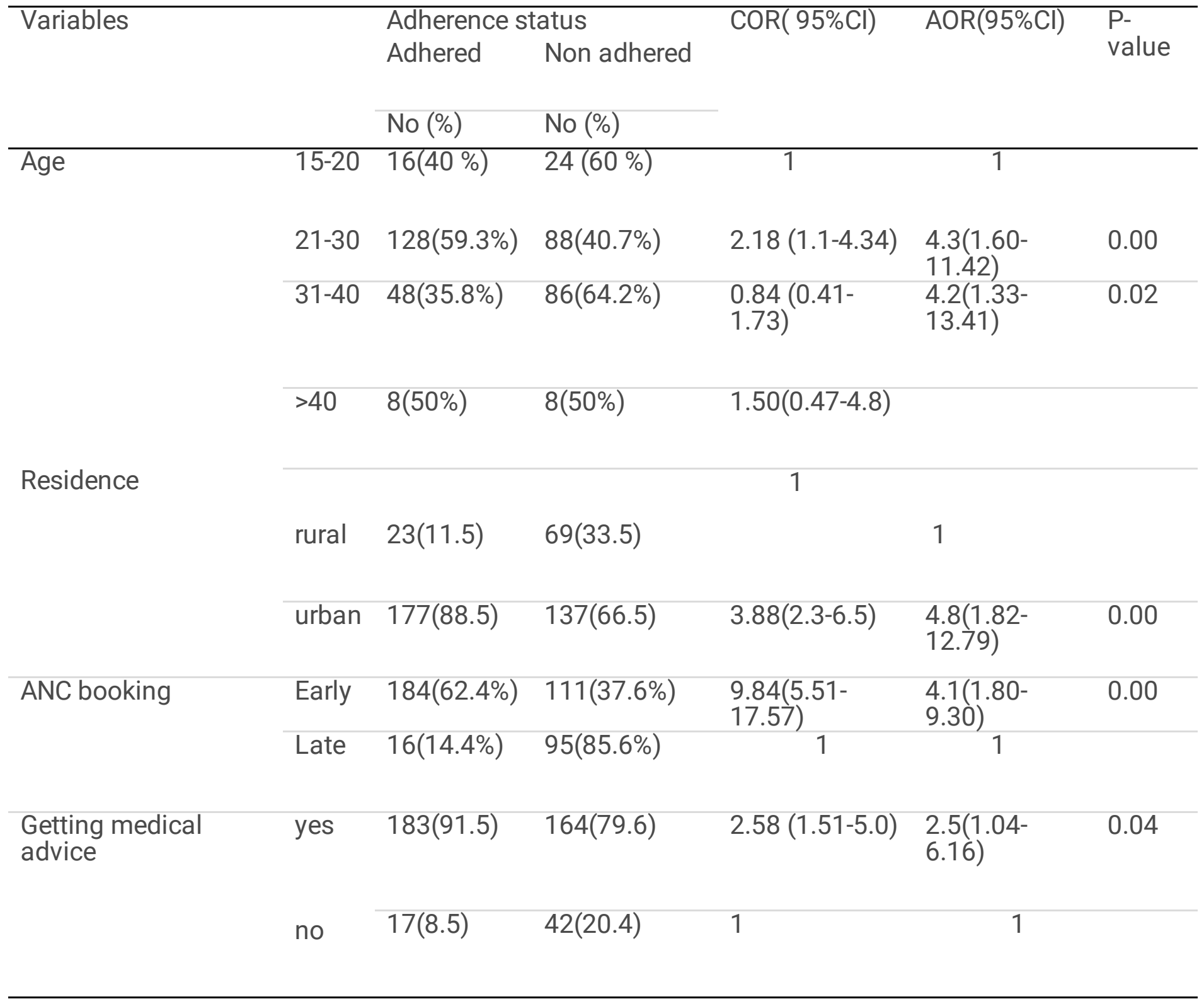

\section{Discussion}

In Ethiopia, all women who seek ANC services from government health facilities receive iron folic acid tablets for free. In this study, $(49.3 \%(95 \% \mathrm{Cl}=44.3 \%-54.2 \%)$ of the pregnant women adhered to IFA supplementation. This finding is higher than the findings from other areas of Ethiopia; Mecha (20\%), Mishan (39\%) and Tigray $(37.2 \%)[9,10,11]$. This finding is also lower than the study conducted in different regions of Nigeria (65.9\%), Senegal (69\%), and Philippines (70\%) [12, 13, 14].The probable explanation might be their difference in living situation and the time gap between studies and study subjects. 
In this study older women were more likely to use iron-folic acid supplementation than younger women. Compared to women aged 15-19, those women women aged 21-30 and women aged 31-40 were about 4.3 times $(\mathrm{AOR}=4.3,95 \% \mathrm{Cl}=1.60-11.42)$ and 4.2 times $(\mathrm{AOR}=4.2,95 \% \mathrm{Cl}=1.33-13.41)$ more likely to be adhered with IFA utilization respectively. This finding is consistent with study conducted in Khartoum, Sudan (15). The explanation could be, the fact that awareness and level of decision making increases with age.

Compared to women who live in the rural areas, those women living in the urban areas were about 4.8 times $(\mathrm{AOR}=4.8,95 \% \mathrm{Cl}=1.82-12.79)$ more likely to be adhered with IFA utilization. The result is supported by the study done in Tigray and Gondar, Ethiopia $(11,16)$.It might be due to the urban location and geographical accessibility and availability of nearby health services and greater media exposure compared with rural areas

Women having early ANC booking were about 4.1 times $(A O R=4.1,95 \% \mathrm{Cl}=1.80-9.30)$ more adhered for IFA utilization than women having late ANC booking. This result is consistent with the studies done in Bicol Philippines, Ethiopia, Tanzania, India, and Honduras [17, 18, 19, 20, and 21].This is explained by pregnant women who start antenatal care follow up early might have better understanding to identify and mitigate pregnancy related problems that can harm mother or fetus may lead to take IFA appropriately

Counseling on the health benefits of supplementation significantly increased adherence with IFA. Women who had got medical advice about IFA utilization were 2.5 times $(A O R=2.5,95 \% \mathrm{Cl}=1.04-6.16)$ more likely to be adhered than who didn't get medical advice. This finding is consistent with the study conducted in Senegal (13). The possible explanation might be that women getting medical advice about the importance of IFA utilization from health providers could encourage them to take the tablet as prescribed.

\section{Conclusions And Recommendations}

The adherence of iron and folic acid supplementation is lower than what it should normally be. Residence, maternal age, early ANC booking and getting medical advice were significantly associated with adherence to iron and folic acid. Intervention modalities that could touch the above factors were highly recommended to increase adherence level of the mothers to Iron/Folic Acid supplementation.

\section{Limitations Of The Study}

Since the adherence level of iron and folic acid supplementation was determined by only considering women's response, the result of the study might be affected by reporting bias.

\section{List Of Abbreviations}

ANC: Antenatal Care, AOR: Adjust Odds Ratio, COR: Crude Odds Ratio, IFA: Iron Folic Acid 


\section{Declarations}

Ethics Approval and consent to participate

This study was approved by ethical review board of Debre Tabor University and permission was obtained from Libo kemkem district health office. Written informed consent was obtained for age group $>18$ year old and parental consent was obtained for age less than 18 year prior to data collection.

Consent for publication

Not applicable

Availability of data and material

The datasets generated during the current study are available from the corresponding author on reasonable request.

Competing interests

We, the authors declare that we didn't have competing interests.

\section{Funding}

The authors have no support or funding to report

\section{Authors' contributions}

TL conceived the study, develops the proposal, collected data, analyzes and interprets data, wrote the draft of the manuscript. YG,YG and AA analyzed the data, drafted and critically reviewed the manuscript. All authors read and approved the final manuscript.

\section{Acknowledgement}

We would like to acknowledge Debre Tabor University for giving a chance to undertake this study. We are also thankful to all data collectors and supervisors for their commitment and research participants for their time. We also extend our gratitude to the study participants for sharing the information.

\section{Authors' information}

Tewachew Muche Liyeh(TL) :Lecturer ,Department of Midwifery, college of health sciences, Debre Tabor University, Debre Tabor, Ethiopia. Email:tewye2006@gmail.com

Yibeltal Abebe(YA):Department of Midwifery,Tibebe Gion Hospital,Bahirdar Ethiopia Email:yibeltalabe@gmail.com 
Yitayal Ayalew Goshu (YG): Lecturer ,Department of Midwifery, college of health sciences, Debre Tabor University, Debre Tabor, Ethiopia.

Email: ayalewyitayal@gmail.com

Amare Simegn Ayele (AA): Lecturer ,Department of Midwifery, college of health sciences, Debre Tabor University, Debre Tabor, Ethiopia.

Email: amaresimegn99@gmail.com

\section{References}

1. Stoltzfus RJ, Dreyfuss ML. Guidelines for the use of iron supplements to prevent and treat iron deficiency anemia, vol. 2. Washington DC: Ilsi Press;1998.

2. World Health Organization. Mother-baby package: implementing safe motherhood

3. Marti CL, et al . Prevalence of anemia during pregnancy: Results of Valencia (Venezuela) anemia during pregnancy study, 2002.

4. McLean $\mathrm{E}$, et al. Worldwide prevalence of anemia, WHO vitamin and mineral nutrition information system, 1993-2005. Public Health Nutr. 2009;12(4):444-54.

5. Badham J, Zimmermann MB. In: Kraemer K, editor. The guidebook nutritional anemia. Basel: Sight and Life; 2007.

6. Central Statistical Agency of Ethiopia. Ethiopia demographic and health survey 2016. Addis Ababa and Calverton: CSA Ethiopia and MEASURE DHS-ICF Macro; 2017.

7. Zakia MI, El-Hamid SA, Mikhail H, Maged SK. Assessment of Adherence to Iron and Folic Acid Supplementation and Prevalence of Anemia in Pregnant Women Ismailia governorate. Egypt Med $\mathrm{J}$ Cairo Univ. 2011;79(2):115-21.

8. Begum S. Factors associated with adherence to iron folic acid supplementations during pregnancy in Uttar Pradesh. Indian J Matern Child Health. 2012;14(2):8.

9. WHO, Daily iron, and folic acid supplementation in pregnant women, 2012.

10. Federal Ministry of Health $(\mathrm{FMOH})$ of Ethiopia. A a national guideline for control and prevention of micronutrient deficiencies. Addis Ababa: FMOH; 2004.

11. Taye B, Abeje G, Mekonen A. Factors associated with compliance of prenatal iron folate supplementation among women in Mecha district, Western Amhara: a cross-sectional study. Pan Afr Med J. 2015;20(1):43.

12. Arega SA, Gebretsadik LA, Hussen MA. Compliance with iron folate supplement and associated factors among antenatal care attendant mothers in Misha district, south Ethiopia: community based cross-sectional study. J Environ Public Health. 2015;2015:7.

13. Gebre A, Afework M, Belachew E. Assessment of factors associated with adherence to iron-folic acid supplementation among urban and rural pregnant women in North Western Zone of Tigray, Ethiopia: 
comparative Study. Int J Nutr Food Sci. 2015;4(2):161-168. doi: 10.11648/j.ijnfs.20150402.16.

14. World Health Organization (WHO) Weekly iron-folic acid supplementation (WIFS) in women of reproductive age: its role in promoting optimal maternal and child health. Position statement.Geneva: WHO press; 2009.

15. Seck BC, Jackson RT. Determinants of compliance with iron supplementation among pregnant women in Senegal. Public Health Nutr. 2008;11:596-605.

16. Lustsey PL, et al. Iron supplementation compliance among pregnant women in Bicol, Philippines. Public Health Nutr. 2007;11(1):76-82.

17. Hala Abdullahi, et al. Antenatal iron and folic acid supplementation use by pregnant women in Khartoum, Sudan, BMC Res Notes. 2014; 7: 498

18. Tesfaye Molla Birhanu et al. Compliance to iron and folic acid supplementation in pregnancy, Northwest Ethiopia, BMC Res Notes. 2018; 11: 345.

19. Farrell B, Merkley VF, Ingar N. Reducing pill burden and helping with medication awareness to improve adherence. Can Pharm J Revue des Pharmaciens du Can. 2013;146(5):262-269.

20. Meselech AD et al. Folic acid usage and associated factors in the prevention of neural tube defects among pregnant women in Ethiopia: cross sectional study

21. Ogundipe $\mathrm{O}$, Hoyo C, stbye T, Oneko O, Manongi R, Lie RT, et al. Factors associated with prenatal folic acid and iron supplementation among 21,889 pregnant women in northern Tanzania. BMC Public Health. 2012;12:481.

22. Roy MP, Mohan U, Singh SK, Singh VK, Srivastava AK. Socio-economic determinants of adherence to iron and folic acid tablets among rural ante- Natal mothers in Lucknow, India. Natl J Community Med. 2013;4(3):386-91.

23. Popa AD, Niţă O, Graur LI, Popescu RM, Botnariu GE, Mihalach L. Nutritional knowledge as a determinant of vitamin and mineral supplementation during pregnancy. BMC Public Health. 2013;13:1105. 